\title{
Médiévales
}

Langues, Textes, Histoire

45 | automne 2003

Grammaires du vulgaire

\section{Alain Boureau, La Loi du royaume : les moines, le droit et la construction de la nation anglaise (XI ${ }^{e}$-XIII ${ }^{e}$ siècles)}

Paris, Les Belles Lettres, 2001, 248 p.

\section{David Bates}

\section{(2) OpenEdition}

Journals

Édition électronique

URL : https://journals.openedition.org/medievales/965

DOI : $10.4000 /$ medievales.965

ISSN : 1777-5892

Éditeur

Presses universitaires de Vincennes

Édition imprimée

Date de publication : 16 septembre 2003

Pagination : 174-175

ISBN : 2-84292-146-1

ISSN : 0751-2708

Référence électronique

David Bates, «Alain Boureau, La Loi du royaume : les moines, le droit et la construction de la nation anglaise (xle-xIII siècles)», Médiévales [En ligne], 45 I automne 2003, mis en ligne le 09 décembre 2005, consulté le 22 avril 2022. URL : http://journals.openedition.org/medievales/965 ; DOI : https://doi.org/ 10.4000/medievales.965

Ce document a été généré automatiquement le 22 avril 2022.

Tous droits réservés 


\title{
Alain Boureau, La Loi du royaume : les moines, le droit et la construction de la nation anglaise (XI ${ }^{e}-\mathrm{XIII}^{e}$ siècles)
}

Paris, Les Belles Lettres, 2001, 248 p.

\author{
David Bates
}

1 Alain Boureau commence son livre avec une observation de Jacques Le Goff selon laquelle «L'Angleterre est un pays bien étrange». Cet apparent exotisme de l'Angleterre est un thème fréquemment remarqué. Il y a douze ans, un autre érudit continental qui étudiait la Common Law, le Belge, Raoul van Caenegem, dans un article ignoré d'Alain Boureau, le rappelait d'une manière encore plus évocatrice. En citant François-Louis Ganshof, il écrivait que l'Angleterre est un pays où les règles universelles ne s'appliquent pas. Cet intérêt pour un sujet fondamental de l'histoire de l'Angleterre, jusqu'ici le quasi-monopole des Britanniques et des Américains, mérite un accueil enthousiaste. Même si le sujet principal du livre est la spécificité anglaise, l'approche d'Alain Boureau met l'accent sur l'évolution européenne du xiie siècle et sur l'originalité anglaise dans ce contexte. Surtout, il souligne un concept assez original qu'il appelle « l'abstraction judiciaire », l'analyse des normes des conflits racontés dans les chroniques des moines. Cette abstraction «s'élabore au terme d'un effort de schématisation » (p. 19). Son champ d'enquête est donc assez restreint en comparaison des livres récents de S. F. C. Milsom et de John Hudson et des articles de Paul Brand et de Paul Hyams2. Il essaie tout de même d'approfondir la connaissance et d'élargir le discours.

2 Après une introduction stimulante, le premier chapitre traite du monachisme anglais et de sa singularité. Même si je ne suis pas entièrement convaincu par ses arguments en faveur de son unité autonome - trop de fondations monastiques ont été d'une date trop tardive et n'ont pas des rapports étroits avec la monarchie - la centralisation précoce du royaume anglais et la quantité remarquable des productions littéraires des abbayes fondées avant la conquête de 1066 justifient l'enquête. Le sujet du second chapitre est l'évolution de l'idée de la nation anglaise. Il est suivi par plusieurs narrations de cas 
spécifiques qui éclairent le thème central du livre en commençant par la dispute entre Guillaume le Roux et l'évêque Guillaume de Saint-Calais en 1088, et en continuant avec, entre autres, l'affaire du marais de Crowland (1189-1202), la rédaction des coutumiers monastiques et la vacance abbatiale entre 1212 et 1215 du monastère de Bury St. Edmunds. La richesse de l'argumentation et l'originalité de la thèse générale du livre doivent être soulignées. L'objet central du discours, en un accent assez banal, mais absolument nécessaire, est relatif à la centralisation de la monarchie anglaise et à ses conséquences. D'une importance égale, partagée avec d'autres études récentes, notamment celle de Paul Hyams, est la réaction contre une insularité anglaise; les moines, comme beaucoup d'autres, ont lu et sont influencés par le droit romain et le droit canonique autant que par les conditions anglaises dans lesquelles la Common law s'est développée3. On peut suggérer qu'en mettant l'accent essentiellement sur la période de la fin du xiie siècle et du commencement du xiii ${ }^{\mathrm{e}}$ siècle, l'ouvrage nous fournit une chronologie discutable et un traitement des sources trop positif. Dater des années 1170 une déclaration selon laquelle « Il ne suffisait plus de prier et d'inventer, il fallut désormais plaider» (p.112) affaiblit les arguments selon lesquels «l'abstraction judiciaire » a existé plus tôt. Comme l'a souligné récemment John Hudson, le Domesday Book (1086) contient de nombreuses références aux laïques et aux moines qui ont plaidé selon des normes4. La période suivante doit être caractérisée en partie comme une révélation plus explicite des normes existantes. On notera des erreurs. La Gesta Guillelmi de Guillaume de Poitiers n'a pas été « rédigée en vers» (p. 111). La Collectio Lanfranci n'a pas été rassemblée par Lanfranc lui-même (p. 98). De temps en temps, l'auteur rend les noms des Britanniques d'une manière fort étrange; on n'appelle jamais de ce côté de la Manche S. F. C. Milsom «Stroud Milsom». Mais La Loi du Royaume constitue une contribution importante et stimulante à l'histoire d'un des grands mouvements de l'histoire de l'Angleterre et de l'Europe. 